\title{
Morin e Flusser: a teoria da imagem como aventura antropológica e matemática imaginária
}

\author{
Rose de Melo Rocha ${ }^{1}$
}

Resumo: $\mathrm{O}$ artigo analisa as contribuições de Edgar Morin e Vilém Flusser à construção teórica da relação entre imagens e imaginário. Articula, com tal objetivo, as ideias de aventura antropológica e matemática imaginária, problematizando, entre outros aspectos, o lugar da racionalidade, da consciência e da autonomia nas sociedades contemporâneas, tributárias, em termos hegemônicos, de verdadeiras patologias da literalidade. Defende-se a conformação "desordenadora" do imaginário como possível rota de fuga, vital e analítica. Criticam-se as prerrogativas empiristas de análise das imagens, recorrendo-se à união fundante imagem/ imaginário como reguladora desse estreitamento.

Palavras-chave: imagem; imaginário; antropologia

Abstract: Morin and Flusser: image theory as an anthropological adventure and imaginary mathematics - This article analyzes the contributions of Edgar Morin and Vilém Flusser to the theoretical construct of the relationship between images and the imaginary. To this end, I articulate the ideas of "anthropological adventure" and "imaginary mathematics," discussing, among other things, the aspects of rationality, awareness and autonomy in contemporary societies characterized, in hegemonic terms, by veritable pathological literalness. I defend the idea of disordered conformation of the imaginary as an escape route, both vital and analytical, and criticize the empiricist prerogatives of iconographic analysis, resorting to the underlying union of image and imaginary as a regulator of this consolidation.

Keywords: image; imaginary; anthropology

1 Artigo originalmente apresentado no Grupo de Trabalho "Imagem e Imaginário", do XX Encontro da Compós, na UFJF, Juiz de Fora, MG, em junho de 2012. 


\section{Morin: imagem e aventura antropológica}

Conforme me despego da terra, o medo se afasta. Eram as raízes que me enchiam de terror.

Tatiana Salem Levy

Edgar Morin tornou-se, décadas atrás, referência imprescindível no campo da comunicação. Os motivos do encantamento foram vários. Destaco aqui aquele que particularmente considero sedutor no trato da relação entre imagens e imaginário. Ao analisar as imagens - aquelas tornadas representações, as que primitivamente habitaram nosso campo inconsciente e nossas visagens -, o estudioso francês, brasilianista por opção, as associa à própria constituição do antropos. Ou seja, na derivação moriniana, seria impossível pensar o homem e sua trajetória de fazer mundo sem considerar o momento fundante no qual começamos a produzir e consumir imagens.

O homem imaginário a que se refere o autor é igualmente um ser imageante. Nossa busca constante de enfrentamento da morte, fonte de libertação e de angústia, cerne de nosso pavor e de nossa potência, estaria intrinsecamente associada a essa capacidade de imaginar e de produzir imagens. Como ele nos esclarece, ao construir teoricamente sua célebre categoria do "homo sapiens-demens", a brecha antropológica está ligada a um processo e a um progresso (cf. MORIN, 2000).

O processo a que se refere Morin articula-se ao que ele considera as duas novidades do sapiens: a sepultura e a pintura. Assim, desse processo fariam parte três gestos, todos referidos à morte e aos mortos, mas também vinculados às tentativas de sua superação: enterrar, adornar e representar. O progresso, justamente, está na consciência de tempo que adquirimos com esse processo, consciência esta que se associa à percepção da passagem de um estado a outro: vivo/morto.

A irrupção do imaginário, como percepção do real, e do mito, como visão de mundo, seriam formas de realizar a transposição (a outro estado), e, para isso, passamos a contar com um aparelho para enfrentar a morte: o aparelho mitológico-mágico. Os ritos da morte, tão caracteristicamente humanos, revelam uma dupla articulação da consciência, própria dos homens de "cérebro grande". Tornamo-nos capazes de articular, ao mesmo tempo, o plano da consciência objetiva - que reconhece a morte - e o plano da consciência subjetiva - que afirma a transmortalidade. É justamente desse jogo objetivo/subjetivo que emerge a brecha antropológica, também matriz do confronto entre o universal - a morte como regra geral - e o singular - a imortalidade como afirmação da individualidade.

Régis Debray (1993), em seus estudos sobre a midiologia, recorre a ideia similar para compreender as fundações primeiras da crença nas imagens. Nos argumentos do autor, o que a morte decompõe é recomposto pela imagem. Somente o que passa quer 
permanecer, escreve Debray. Não apenas sistemas de crença visual se estabelecem aqui, igualmente consolidam-se regimes de poder potentes, legislando sobre o que teria direito à visibilidade e o que estaria fadado à invisibilidade. Imagens para olhos de poucos, nesse contexto, também consolidariam regimes de adoração restritos, como em um clã de imagens destinadas a mui seletos observadores.

Discorrendo sobre a natureza do que ele chama aflição mágica, Debray entende ser a representação um recurso de negociação com as forças ocultas e com os fenômenos imprevisíveis. Mediadora entre os vivos e os mortos, entre humanos e deuses, a imagem não seria um fim em si, mas um meio de sobrevivência. Nesse aspecto, o raciocínio do autor leva-nos a uma interessante associação: nas sociedades sem cadáveres e sem esqueletos - as nossas -, que baniram a morte do campo de visão, o que nos resta são os fluxos de imagens, capazes de seduzir e apreender olhares demasiado protegidos. Poder-se-ia acrescentar: olhares protegidos e bastante narcisistas, estes que baniram os espectros para adorar os espelhos e, em um segundo momento, cultuar as imagens.

É interessante comparar as leituras acima com o que nos diz Morin (2000). Acompanhando Morin em seu raciocínio, temos que o sepultamento, bem como ritos e materialidades a ele associados, configuram a primeira grande entrada do humano na casa da representação. A pintura, prima-irmã desse processo, significa em Morin a concretização de um segundo nascimento, no qual do mundo prático chegamos ao mundo simbólico. Pinturas, desenhos, símbolos, todos designam um campo novo do saber-fazer, o das produções do espírito, contemplando as imagens, os símbolos e as ideias.

No argumento do antropólogo, as imagens, por exemplo, devem ser lidas em uma via de mão dupla. Diferentemente de Debray, Morin defende que, sim, as imagens possuem um sentido em si, pela via estética. Todavia, um sentido delas emerge, ao mesmo tempo, em função de finalidades específicas, como na via mágica ou ritualística. Com essa observação, podemos compreender como a irrupção do "homem imaginário" é a sentença definitiva que sela a união entre imagens e imaginário. Gestada remotamente pelo trânsito dos duplos no mundo dos vivos - por nossas sombras, espectros, sonhos e aparições - assiste progressivamente à entrada em cena da materialização dos duplos.

Não por acaso, essa entrada em cena, progressivamente, vai dar margem à associação entre representações visuais e magia. Lembrando Walter Benjamin, é pela via de sua reprodutibilidade técnica que imagens "des-auratizadas" vagam pelo mundo dos humanos como aparições fantasmáticas. Sem aura, mas plenas de valor de exposição, conduzem os duplos ao cotidiano, Ihes dá vida e concretude, ao mesmo tempo que os fetichiza. Há aqui um interessante fio a ligar os vodus às imagens televisivas, por exemplo. Há aqui, igualmente, um forte traço da constituição imaginária de nossos modos de produzir e consumir imagens.

Anos atrás, ao perseguir essa pista analítica, propus a metáfora da cartola de mágico para analisarmos a mídia (ROCHA, 2004). Ou, se quisermos anunciar o diálogo que será 
proposto a seguir, como cartola de um mágico que, na verdade, é um enganador, posto que se encontra a serviço de um grande programa de desabstratificação do mundo. À dupla constituição dos objetos, ao mesmo tempo artefatos e representações, podemos vincular a dupla constituição das imagens, como representações e artefatos. A imagem técnica é o epicentro de um tensionamento irrefreável dessa constituição, e sobre esse aspecto vou deter-me na segunda parte deste artigo.

Segundo Morin, o sapiens é portador (biologicamente) e produtor (culturalmente) de um fenômeno estético, sendo a sensibilidade estética conectada a nossa capacidade de entrar em "ressonância":

A estética é uma relação que se estabelece entre o ser humano e uma certa combinação de formas. [...] A sensibilidade estética é bem uma aptidão para entrar em ressonância, em "harmonia", em sincronismo, com sons, odores, formas, imagens, cores, que são profundamente produzidos não só pelo universo, mas também, daqui por diante, pelo Homo sapiens (MORIN, 2000, p. 103).

Essa visão arejada da estética, percebida como fenômeno e experiência sensóriocognitiva, afina-se com a compreensão de um princípio de conceituação do imaginário. A aventura imaginária, nesse ponto de vista, é própria de seres dotados de racionalidade e consciência, capacitados tanto a interpretar o mundo em si quanto a interpretar símbolos, e, mais ainda, capazes de dúvida e ilusão, pilares da nossa primordial "zona de incerteza". Como reivindica Morin,

A zona de incerteza entre o cérebro e o ambiente também é a zona de incerteza entre a subjetividade e a objetividade, entre o imaginário e o real, e fica ainda mais aberta pela existência da brecha antropológica da morte e pela irrupção do imaginário na vida diurna (MORIN, 2000, p. 104).

Não por acaso, torna-se premente, em sociedades midiáticas ${ }^{2}$ e discursivas, o debate incansável acerca das "patologias da literalidade" que proliferam no cotidiano, ultrapassando fronteiras de classe e de credo. Os profetas da objetividade, antes de serem devotos da razão, representam, paradigmaticamente, setores da sociedade que desaprenderam, a um só tempo, a capacidade da racionalidade e da consciência. Nós, comunidade dos animais dotados de descomedimento, parecemos, por vezes, pender nossa bússola para os sentimentos do furor e da destruição, minimizando, a alto custo, a capacidade da criação e da partilha.

2 Nos cenários contemporâneos a midiatização do social e a centralidade do agenciamento da visibilidade social por, entre outros, os aparelhos de representação massivos e os meios digitais, de base descentralizada, fazem conviver manifestações imagéticas e audiovisuais de larga diversidade. Assim, expressões culturais de base ritualística, tradições residuais, expressões artísticas emergentes, entre outros, atravessam e são atravessadas por fluxos midiáticos, ora ressignificando-os, ora por eles sendo ressignificados. As palavras de ordem que dão gramatura sociocultural à lógica do capital não constituem, obviamente, um sistema absolutamente pleno, fechado, de poder absoluto. Como defendemos neste artigo, as irrupções de brechas e de insubordinações são a prova mais cabal da força do descomedimento humano no traçado das resistências e das ações contra-hegemônicas. 
A máxima empirista "uma imagem vale mais que mil palavras" foi uma sentença cruel imposta a nosso celeiro de visualidades, retirando-lhes a ambiguidade e extirpando-Ihes as contradições. Liquidou-se em uma única cajadada a indissociação imagem/imaginário e a compreensão do olhar como forma essencialmente errante de conhecer o mundo. As imagens que contaminam o real não são de qualquer natureza: elas, invariavelmente, respondem ao plano da literalidade. Fazem ver para fazer crer. $\mathrm{E}$ em quê? Na verdade $\_$nelas mesmas. Triunfo do simulacro. Obliteração da consciência. Falsa consciência. Falsa objetividade.

Mas esses ícones da objetividade, ainda que respondendo a um projeto hegemônico, não estão sós. Imagens podem também ser insubordinadas. E o são por uma prerrogativa: imagens são produtos e produtoras de imaginários. Marc Augé (1998), em um de seus livros mais herméticos, A guerra dos sonhos, pinta-nos um cenário aterrador, detonado, segundo sua hipótese pela penetração indiscriminada de imagens em nosso dia a dia. Radicalizando proposições que, na década de 1960, tornaram-se célebres pela voz do pensador do espetáculo Guy Debord (2000), Augé postula termos chegado ao grau máximo da colonização e da apatia autoimputada. Agora, mais do que "uma relação social entre pessoas, mediada por imagens" (DEBORD, 2000), é da nossa capacidade imaginária que estaríamos abrindo mão.

Segundo Augé, o regime imaginário foi de tal modo escrutinado pela mídia massiva que se teria colocado na berlinda nossa memória, nossa imaginação e até mesmo nossos sonhos. Grande metanarrativa a ordenar o socius, o regime midiático teria se tornado um poderoso agenciador dos imaginários coletivos - dos mitos, ritos e símbolos - e dos individuais - dos sonhos propriamente ditos. Sobre essa amnésia coletiva, Augé afirma que o desenvolvimento das tecnologias comunicacionais liberou um processo de ficcionalização da vida, que concorre para a perda da memória e do imaginário. Nesse processo, o esmaecimento da nitidez que permitiria discernir o real do ficcional leva a um processo de mimetização curioso, no qual a nossa própria percepção e a capacidade de relatar o mundo vivido seriam nada mais do que uma reprodução introjetada dos discursos midiáticos.

Morin não é tão pessimista. Condescendente e até mesmo entusiasta defensor do encanto das imagens (MORIN, 1997), nelas identifica a expressão positiva da colagem entre o empírico e onírico. Analista da sedução desempenhada pelas "imagens do real", do "já visto" transformado em imagem, problematiza, humanizando-o, o culto às imagens, e nele não vislumbra apenas dinâmicas opressivas. Antes, a magia fotogênica é permeada por quinhões de memória, por possibilidades de recordação do vivido e de projeção do futuro.

Negociando temores e indicando perspectivas simbólicas de sua superação, a entronização das imagens possuiria, em um de seus braços, a marca da adoração e do fetiche, recursos de dominação e posse do mundo, e aqui, novamente, a figura do duplo se faz presente: esse é o universo da atribuição às imagens materiais de qualidades mentais. 
Em meio a essas fantasmagorias, nossa relação com as imagens é marcada tanto pela fascinação quanto por experiências alucinatórias, como na transformação de estrelas do cinema em duplos. A "coisificação" do humano é o primeiro requisito para a atribuição de anima às imagens. Imagens das estrelas do show business, trafegando solenes em tapetes vermelhos ou tropeçando embriagadas em saídas noturnas, comporta, de fato, um duplo movimento: estamos diante de coisas, de sujeitos-objetos, e estamos diante de imagens, de objetos-sujeitos.

Nesse delírio da representação, podemos argumentar que a própria realidade se estetiza. No universo dos corpos-imagens, as imagens-corpos parecem assumir um estranho protagonismo. O encanto dá lugar aos imaginários da visibilidade compulsória, predatória, utilitarista. A imagem se fetichiza e o olhar sucumbe à lógica das telas, das superfícies e da máquina. No lugar da "imagem do real" há imagens de imagens, como em uma espiral sem fim.

\section{Flusser: imagem e matemática imaginária}

A estrada é cerrada, feita de curvas e mais curvas, em precipício. Basta um deslize, e o carro despenca até o mar. Um deslize, e a morte.

Tatiana Salem Levy

Do homem imaginário de Morin chegamos ao conceito de imaginação em Vilèm Flusser (2002). Segundo explica o próprio Flusser, já nas páginas iniciais de seu Filosofia da caixa-preta, "a imaginação é a capacidade de decodificar fenômenos de quatro dimensões em símbolos planos e decodificar as mensagens assim codificadas. Imaginação é a capacidade de fazer e decifrar imagens" (FLUSSER, 2002, p.7).

A partir do momento em que, como diria Flusser (2002), o homem passa a existir como sujeito, aquilo que ele vê (ou escuta, sente etc.) é "representação" não apenas por "intuição", mas igualmente por "imaginação". Bernardo (2005) observa que "Flusser não reconhecia diferença significativa entre imagem e realidade. Ele tinha aversão ao termo simulação, porque entendia implicar uma ideia do real teoricamente insustentável" (BERNARDO, 2005, p. 16).

Para desenvolver esse debate, comparemos as duas definições que Flusser apresenta para o termo imaginação. Ela tanto é a citada "capacidade de fazer e decifrar imagens" (FLUSSER, 2002, p. 7) quanto é a "singular capacidade de distanciamento do mundo dos objetos e de recuo para a subjetividade própria, [...] capacidade de se tornar sujeito de um mundo objetivo" (FLUSSER, 2007, p. 163). A imagem perceptiva - nossa percepção 
do mundo objetivo -, portanto, é híbrida: produto de qualquer coisa que estimule os sentidos, dos modos de funcionamento deles e da intuição/imaginação (cf. ROCHA e PORTUGAL, 2008, p. 163-164).

Defendendo a utilidade do caráter mágico das imagens - o poder de substituírem "eventos por cenas" - para o processo de compreensão do mundo, Flusser, contudo, denuncia os riscos da idolatria, situação na qual "[o] homem, ao invés de se servir das imagens em função do mundo, passa a viver em função de imagens", alienando-se "em relação a seus próprios instrumentos". Nessa estranha situação, a "[i]maginação torna-se alucinação e o homem passa a ser incapaz de decifrar imagens, de reconstituir as dimensões abstraídas" (FLUSSER, 2002, p. 9).

Se Morin localiza nas imagens técnicas, provenientes do cinema e da fotografia, a graça e a força encantatória das primeiras imagens, Flusser propõe uma diferenciação importante, que, nesse aspecto, o faz mais descrente das imagens oriundas dos ambientes midiáticos. Ele nos diz:

Claro está que a magia das imagens técnicas não pode ser idêntica à magia das imagens tradicionais: o fascínio da TV e da tela de cinema não pode rivalizar com o que emana das paredes da caverna ou de um túmulo etrusco. Isto porque TV e cinema não se colocam ao mesmo nível histórico e ontológico do homem da caverna ou dos etruscos. A nova magia não precede, mas sucede a consciência histórica, conceitual, desmagicizante (FLUSSER, 2002, p. 16).

Filhas de uma sociedade e de um projeto programático, as imagens técnicas padecem e portam uma mensagem de alienação e conformismo. Para Flusser, tratar-se-ia de uma "consciência mágica de segunda ordem":

A nova magia é a ritualização de programas, visando programar seus receptores para um comportamento mágico programado. [...]

[A] cultura ocidental se dividiu em três ramos: a imaginação marginalizada pela sociedade, o pensamento conceitual hermético e o pensamento conceitual barato (FLUSSER, 2002, p. 16-17).

Segundo Müller (2009), "a imagem técnica está condicionada a uma série de conceitos: na imagem fotográfica não é a 'realidade' que eu deveria estar vendo, mas os conceitos químico-ópticos que permitem a fixação da imagem no celuloide" (MÜLLER, 2009, p. 142). Para Baitello (2010), Flusser "[sublinhava] uma marca não apenas do aparato técnico, mas também de todo o aparelho social e midiático contemporâneo: a dispensa do pensar e do querer, pois esta tarefa de pensar e de querer é simplesmente assumida pelo aparelho" (BAITELLO, 2010, p. 21). O ciclo se fecha: de devoradores de imagens passamos a devorados. É este o programa: consumar o vazio e a dispensa do pensar e do sentir no ato mesmo de ser consumido por imagens. Esse é o impasse da existência vivido nas sociedades sustentadas na "magia de segunda ordem" das imagens midiáticas. 


\title{
Morin e Flusser: "outridades" e sinergias
}

\author{
Anda soldado \\ Não se demores \\ Vais arrasado \\ Ainda não chores. \\ Mário Cesariny
}

O tcheco Flusser, nascido em Praga no ano de 1920, em uma família de intelectuais judeus, era contemporâneo do parisiense Morin, nascido Edgar Nahoum, em 1921, o único filho de uma família judia sefardita. Em 1940 Flusser perde pais, irmã e avós nos campos de concentração da Alemanha. No ano seguinte, emigra para o Brasil, e naturaliza-se na década de 1950. Durante os primeiros anos, trabalha em uma empresa pertencente à família do sogro, As Indústrias Radioeletrônicas do Brasil Ltda. (IRB).

Membro da Resistência Francesa durante a Segunda Guerra, Morin é transferido para a Alemanha ocupada, durante a Liberação, atuando como adido ao Estado Maior do Primeiro Exército Francês na Alemanha (1945) e, em 1946, como chefe do departamento de propaganda do governo militar francês. Duas décadas separam os primeiros livros que publicaram: Morin, em 1946, Flusser, em 1963. Duas décadas separam a vinda de Flusser ao Brasil do momento em que Morin estreita laços com a comunidade intelectual latino-americana. Morin, ainda atuante, vive hoje na mesma cidade em que nasceu. Em novembro de 1991, Flusser sofreu um acidente fatal de carro nas proximidades de Praga, para onde havia voltado, após 52 anos, para proferir uma conferência na qual falou, arrebatado, "sobre seus sonhos de seres humanos como projetos de programação, como seres sem teto e errantes, que têm de aprender a conquistar as máquinas, entender e dominar seus novos códigos digitais" (BERNARDO, 2005, p. 16).

O método moriniano da complexidade prevê e pressupõe a existência de um sujeito cognoscente que absorve e organiza, como um grande computador, os inputs do ambiente, do bios e da cultura. Segundo Carvalho (2009),

[a] fecundidade do método reside na tentativa de religação dos dispositivos racionais-lógicos-dedutivos e míticos-mágicos-imaginários. [...] Busca-se estabelecer pontos de confluência entre a singularidade da matéria e do espírito que permitam uma visão mais integrada do homem.

O método absorve, convive e dialoga permanentemente com a incerteza. (CARVALHO, 2009, p. 264).

Assim como sua análise da imagem prevê o erro, o descomedimento e a incerteza, sua concepção de ciência provém da brecha antropoética, ou seja, a narrativa científica concilia-se com o universo mágico. Não seria demais lembrar o berço etimológico da 
palavra imagem, este que une IMAGE a MAGIE, assim como o termo "gramática" resvala no parentesco entre GRAMMAR e GLAMOUR ${ }^{3}$.

Defensor da animalidade do conhecimento humano, Morin também associa o progresso intelectual à "multiplicação das comunicações de todos os tipos", que:

tece uma rede social cada vez mais complexa, a qual permite o crescimento das comunicações e favorece o desenvolvimento dos indivíduos, o qual favorece o da complexidade social. Assim, nos mamíferos e nos primatas, e ao longo da hominização, não se pode separar o desenvolvimento do conhecimento e da inteligência do desenvolvimento das interações sociais (MORIN, 1999, p. 83)

O pensamento de Flusser, por sua vez, está ancorado na ideia de um mundo codificado, constituído a partir de relações de comunicação, viabilizada, justamente, pela existência de sistemas simbólicos. Mas, na trilha de Morin, Flusser também foi um insubordinado. Recusava as fronteiras disciplinares rígidas, desconfiava de conceitos de Real que se despregassem do princípio da programação. Real, construto, aparelhos, máquinas e gramáticas imaginárias. Para Flusser, a libertação da arte estava em forçar a inversão dos programas previstos para os aparelhos e a libertação da ciência em um procedimento que poderíamos nomear de "codigoclasmo". Localizamos esse princípio em suas reflexões críticas acerca da textolatria, "tão alucinatória como a idolatria":

Exemplo impressionante de textolatria é a 'fidelidade ao texto', tanto nas ideologias (cristão, marxista etc.), quanto nas ciências exatas. Tais textos passam a ser inimagináveis, como é o universo das ciências exatas: não pode e não deve ser imaginado. No entanto, como são imagens o derradeiro significado dos conceitos, o universo da ciência torna-se universo vazio (FLUSSER, 2002, p. 11) .

Recorrendo a Flusser, temos que os aparelhos técnicos e seus aparatos comunicacionais ancoram-se em fundamentos sedutores, em uma magia imagética de nova ordem. Para Morin, tratar-se-ia de um caminhar em duplo registro: imagens que nos reconduzem e dão sentido ao nosso cotidiano; as mesmas imagens que nos permitem o salto - fantasmagórico ou alucinatório - para além das pequenas rotas do dia a dia, magicizando sonhos miúdos.

Em estudos anteriores sobre a arrebatação capitaneada por imagens técnicas ${ }^{4}$, associei o olhar e o perceber-se no mundo - o comunicar - a estratégias de diálogo com e no mundo marcadas e demarcando incansáveis dinâmicas ou ainda lutas por deter o controle das mediações entre o que se vê e o que se pode constituir como visível. Os humanos, seguindo esse raciocínio, comunicam por necessidade, pela mais absoluta necessidade de sobrevivência psíquica.

3 Segundo Peter Sloterdijk, "a expressão para 'magia' emerge [no inglês medieval] da palavra para 'gramática'. [glamour, originalmente com o sentido de 'encantamento', 'feitiço', provém de glammar, variante por dissimilação de grammar, no sentido de 'conhecimento oculto'. N.T.]".(SLOTERDIJK, 2000, p. 11).

4 Para uma recuperação sintética desta linhagem reflexiva, recomendo a consulta aos artigos que tenho apresentado nos Encontros da Compós (http://www.compos.org.br/). 
Precisam crer e, mais ainda, precisam de fato realizar uma apreensão do mundo e de si mesmos através de imagens e, finalmente, como que para suportar sua insignificância, precisam crer na materialidade de suas representações. Precisam, finalmente, acreditar que tais imagens são mundo. Esse real de imagens dilata-Ihes a existência, permite o exercício de uma dominação através do olhar, garante-lhes a mirada sobre sua própria duração, ela própria ampliada, visualmente eternizada.

Edgar Morin fala de um susto do sapiens para designar a inadequação constitutiva de nossa espécie - a imersão/afastamento da natureza. Em Vilém Flusser encontramos um interessante aprofundamento que associa os processos de comunicação imagéticos exatamente à incerteza que nos constitui. Para Flusser (2002), o mal-estar da humanidade é extensamente vinculado a um mal-estar da visualidade.

A imortalidade das imagens, que inicialmente nos salvou da morte, eternizando-nos, pode, agora, nos oprimir. Hiper-reais, pós-espetaculares, são sequestradoras de anima. "Grande e grosso" foram as palavras de uma mulher-imagem a um homem-imagem, fala capturada após a consumação de um ato sexual, supostamente tornado público por um erro dos programadores do sistema, no caso, os editores do reality show Big Brother Brasil 12 (Rede Globo). O homem-objeto-imagem responde, satisfeito: "devíamos fazer isso todo dia". E provavelmente o farão: esse sexo-imagem, esse sexo-marketing, sexo que não é a estetização do cotidiano, mas, sim, a afirmação de sua impossibilidade. Sexo que só se viabiliza como imagem, em imagem. O sexo discursivo, imagético, ao vivo, dilatado e estendido. Parodiando Flusser, as imagens do sexo substituem o evento por suas cenas.

Desmontar essa estrutura de poder, ancorada no jogo visível/invisível, não é tarefa para ingênuos, nem seria possível que os "soldados" do programa a levassem a cabo. O remédio, mais uma vez, é a inversão. Onde as imagens-objetos enxergam corpos, vejamos imagens. Onde enxergam imagens, vejamos corpos. Onde enxergam emancipação, lá estará o mais profundo assujeitamento. Onde anunciam a "outridade", ali morará o mesmo. Onde preveem a permanência, mora a transitoriedade. À fala da mulher-imagem, acima apresentada, corresponderia, portanto, uma fala outra, um inexorável não dito. Esse não dito é, justamente, proveniente do plano imaginário que foi extirpado das imagens. Esse não dito denuncia a objetualidade da mulher-imagem e do homem-imagem, condição esta que justamente eles parecem desconhecer. Crendo-se potentes, livres e desafiadores, evidenciam, ao contrário, a servidão voluntária à potência maquínica e aos princípios do programa, que faz ver para menos fazer sentir. No avesso do êxtase do sexo televisionado, executado ao vivo, em imagem, ensaiado, coreográfico, é o imaginário do tédio e da indiferença que prepondera. Que ainda nos restem outros a sonhar.

Rose de Melo Rocha é coordenadora do PPGCOM-ESPM e doutora em ciências da comunicação (USP), com pósdoutorado em ciências sociais (PUC-SP).

rrocha@espm.br 


\section{Referências}

AUGÉ, Marc. A guerra dos sonhos. Campinas: Papirus, 1998.

BAITELLO, Norval. A serpente, a maçã e o holograma. São Paulo: Paulus, 2010.

BERNARDO, Gustavo. O diabo irônico de Flusser. In: Revista Trópico, 21 de abril de 2005.

CARVALHO, Edgard de Assis. Edgar Morin. In: MARCONDES FILHO, Ciro (Org.). Dicionário da comunicação. São Paulo: Paulus, 2009.

DEBORD, Guy. A sociedade do espetáculo. Rio de Janeiro: Contraponto, 2000.

DEBRAY, Régis. Vida e morte da imagem. Uma história do olhar no ocidente. Petrópolis: Vozes, 1993.

FLUSSER, Vilém. Filosofia da caixa-preta. Rio de Janeiro: Relume Dumará, 2002.

O mundo codificado. São Paulo: Cosac \& Naify, 2007.

MORIN, Edgar. O cinema ou o homem imaginário. Lisboa: Relógio D’Água, 1997.

O Método 3. Porto Alegre: Sulinas, 1999.

O paradigma perdido. A natureza humana. Lisboa: Publicações Europa-América, 2000c.

MÜLLER, Adalberto. Vilém Flusser. In: MARCONDES FILHO, Ciro (Org.). Dicionário da comunicação. São Paulo: Paulus, 2009.

REVISTA Nómadas. Dossiê Regímenes de visualidad: emancipación y otredad desde América Latina. Bogotá: Universidad Central, outubro de 2011.

ROCHA, Rose de Melo. A cartola da mídia. Sacando imagens, materializando magias. In. Revista Famecos: mídia, cultura e tecnologia. Porto Alegre: PUC-RS, Programa de Pós-Graduação em Comunicação Social, n. 24, julho de 2004, p.158-165.

; PORTUGAL, Daniel. Trata-se de uma imágica?. In. ARAÚJO, Denise; BARBOSA, Marialva. Imagíbrida. Porto Alegre: Editora Plus.Org, 2008. Disponível em: <http://acervo-digital.espm.br/ebooks/249781.pdf>. Acesso em: 1 maio 2012.

SLOTERDIJK, Peter. Regras para o parque humano. São Paulo: Estação Liberdade, 2000. 